\title{
CORRIGENDUM
}

\section{Two novel cytochrome P450 genes CYP6CS1 and CYP6CW1 from Nilaparvata lugens (Hemiptera: Delphacidae): cDNA cloning and induction by host resistant rice-CORRIGENDUM}

\author{
Z. Yang, Y. Zhang, X. Liu and X. Wang \\ doi: 10.1017/S0007485310000192, Published by Cambridge University Press, 8 July 2010.
}

The authors apologise for the error in the caption of Figure 4, on page 6 of their paper.

The caption should read as follows:

Fig. 4. Detection of CYP6CS1 and CYP6CW1 expression by northern blot hybridization, using the RNA samples extracted from the indicated tissues of the nymphs fed with TN1 and MH63, respectively. (a) An example from northern blot experiments. RPS25 acts as inner reference. The italic words 'RPS25, CYP6CS1 and CYP6CW1' represent probes used in each hybridization experiment. G, FB and C represent the gut tissue, fat body and carcass, separately. TN1 indicates the nymphs fed with TN1 plants and MH63 indicates the nymphs exposed to MH63 seedlings. (b) Spatial induction of CYP6CS1 and CYP6CW1 in N. lugens nymphs exposed to MH63. The mean \pm SD of three determinations of mRNA level in each tissue of $N$. lugens subjected to MH63 relative to that in the corresponding tissue of nymphs ingestion of TN1 were shown as histograms $(\square$, CYP6CS1; $\square$, CYP6CW1).

\section{Reference}

Yang Z. et al. (2010). Two novel cytochrome P450 genes CYP6CS1 and CYP6CW1 from Nilaparvata lugens (Hemiptera: Delphacidae): cDNA cloning and induction by host resistant rice. Bulletin of Entomological Research, Published by Cambridge University Press, 8 July 2010. doi: 10.1017/S0007485310000192. 